\title{
Rethinking the Learning Partnership between Museums and Initial Teacher Training
}

\author{
Vasiliki Tzibazi \\ The University of Winchester, UK
}

\begin{abstract}
Initial Teacher Training (ITT) Institutions have been at the centre of museums' attention since they share common professional grounding and an interest in pedagogy, research and learning. Collaboration between ITT and museums has been also promoted via recent governmental initiatives that view the museum space as an alternative platform for student teachers to broaden their professional practice and experiences in places beyond the traditional classroom. This paper, based on the findings of an empirical study, attempts to explore the issues that might emerge from such partnerships. It suggests that tensions might emerge between ITT and museums when pedagogy is interpreted in a mechanistic sense. The discussion focuses on the potential of museum experiences to offer possibilities for deep learning and the need for both institutions to create a dialogic space that explores possibilities for meaningful partnerships beyond ticking boxes exercises.
\end{abstract}

\section{Introduction}

In recent initiatives launched by the Department for Culture, Media and Sports museums are seen as unique educational institutions which are called to form partnerships with other institutions and community groups in order to both widen their audiences and deepen the quality of their educational offer [1], [2]. In particular, the government consultation paper, 'Understanding the future: Museums and the $21^{\text {st }}$ Century', articulates clearly the need for the museums sector to foster strategic patterns of collaboration with the Higher Education that promote a formalised and systematic exchange between the two sectors in terms of staff, students and scholars [2]. Museums positively welcomed this initiative for cross-institutional work, acknowledging though amongst other factors the difficulty in maintaining long term sustained partnerships with other institutions [3]. However, as stated by Speight (2010) despite the museums' enthusiasm for partnering universities only a few responded to the challenge [4] while traditionally within the museum sector projects with the students from the Higher Education (HE) sector tended to have an ad hoc format based on personal relationships between university tutors and museum professionals [5]. It was this gap that further funding initiatives were called to play such as the strategic commissioning programme launched by the governmental organization for the museums, libraries and archives (MLA) that promoted partnerships between Initial Training Institutions (ITT) and museums.

Although there is a wealth of literature focusing on partnerships between Universities and museums in the UK on the basis of academic research and material culture [7], the area of collaboration between $\mathrm{HE}$ and museums for pedagogical purposes is under-researched [7], [8], [9]. The learning spaces of $\mathrm{HE}$ and museums have only been recently at the centre of debate through collaborative projects between museums and HE programmes in Design Education that raised questions about the conceptual differences and similarities in the learning experiences offered in the two types of institutions [7], [10], [11]. This paper seeks to contribute to the debate by posing questions about the perceptions of pedagogy that inform the collaboration between the institutions, the form of experiences offered and the way these experiences are lived and understood by those affected by such partnerships: the student teachers, the university tutors and the museum professionals.

\section{Museum Pedagogy and the ITT agenda}

The focus on partnerships between museums and ITT could be viewed via its threefold purpose; the museums develop partnerships not only with the HE sector but also 'stimulate demand in schools as well as build supply through developing their own capacity' [12]. It is believed that if student teachers deepen their understanding about the value of teaching outside the classroom then they will embed the use of museums into their future professional practice [13].

Indeed, in the light also of initiatives such as 'Learning outside the Classroom', 'five hours of culture' and the emphasis on cross curricular 
approaches in education, ITT providers seemed to be keen to integrate cultural settings in their course provision to encourage their students to develop the confidence and skills required to engage with the cultural sector. Research commissioned by the Department for Education and Schools (DfES), Natural England the Farming and Countryside Education (FACE) to provide information about the nature of 'training' in Education Outside the Classroom (EOtC) in initial teacher training courses reported that the majority of the ITT institutions in the UK addressed EOtC either in their course provision or indirectly through the student teachers' school placements. However, the embracement of EOtC was not always a straightforward process. Amongst the key issues that emerged within the same report were that ITT could offer more opportunities for EOtC if there was a clearer link between the student teachers' outside the classroom experiences and the Standards that one needs to meet to obtain the Qualified Teacher Status (QTS). There was a sense that there is lack of quality assurance in terms of the way the trainees are prepared for and also experiencing EOtC [14]. To this pessimistic agenda may also contribute the under-theorized realm of EOtC; Dfes (2006) defines 'education outside the classroom', in its broadest sense, 'any structured learning experience that takes place beyond the classroom environment' [14].

Recently set guidelines were produced to coordinate the partnership between museums and ITT to ensure quality in student teachers placements in settings other than schools [15]. The guidance termed as 'Teaching Outside the Classroom' (TOtC) includes amongst the step-by-step guidance for the development of placements, suggestions about the activities that students can undertake in the museum space and provide checklists that ensure the 'range of learner behaviours' that a student teacher needs to demonstrate in order to meet the relevant QTS standards. Evaluation templates are provided that aim, without also excluding the tracing of qualitative and unexpected elements of the experience, to measure the impact the experience has on the student teachers' achievement and its effectiveness accordingly to preset categories and success factors. This set of guidelines might respond to the ITT institutions' need for quality assurance and experiences that meet the QTS standards, however, their focus on preset objectives should not remain unproblematised.

Educational objectives and the forms they take are inextricably linked with the way education and its values are conceptualized. Eisner (2005) by reflecting on the conceptions of education within the past fifty years argues that there are three dominant metaphors that describe the importance and function of educational objectives: these are the 'industrial, behaviorisrtic and biological' metaphors [25]. He argues that the first two metaphors are still prominent today informing the standards-driven culture in education. In particular, the industrial metaphor being imposed in schools for the longest periods in the history of education is associated with the efficiency of educational processes and the introduction of standards against which the value of the educational product is measured by administrators at regular intervals. This perspective viewed the teachers as engineers and the students as the raw material to be processed' against the predetermined 'product specifications' [16]. Within the same mechanistic view of education Eisner also places the behavioristic metaphor in education which emerged with the promise that psychology could employ scientific methods for the study and conduct of education. As a result, it was believed that the process of education could be designed with the view of formulating objectives that could bring changes in observed behavioural terms.

Hence, the eminent focus on perfomative agendas and preset objectives might attribute rigor to the EOtC agenda. With the promise though that the processes of e EOtC can be designed to bring observed behavioural changes to the student teachers, and later on through their own professional practice to bring the desirable changes to their own students, we might loose the eventfulness and openness that make museum visiting a powerful learning experience.

A radically different conception of education, that views educational practice as 'an artful, emerging affair' is implied in Eisner's 'biological metaphor' which rooted in Dewey's views about education is more concerned with supporting children to realise their potential rather than with the attainment of prescribed goals [25]. Learning becomes a process through which we elaborate, experiment and meanings become personalized for everyone involved. Expressive objectives can be set to identify the situation within which students are invited to work without specifying what is to be learnt. Accordingly an evaluation will take the form of reflection on the experience highlighting its uniqueness rather than the application of common standards to what is produced. Thus, if a learning partnership between ITT and museums could unfold within this perspective more space could be given for imaginative, authentic choices and unexpected learning encounters. Perhaps, this is not a utopia since the grounding for this perspective seems to be established within the realm of museum education.

What lies at the heart of the museum pedagogy is a conceptual shift from education as a product to learning as an experience. The raise of the New Museology in the 80s set the agenda for the gradual birth of the 'post-museum' which displayed 'a more sophisticated understanding of the complex relationships between culture, communication, 
learning and identity' and challenged definitions about the museum's purpose and relationship with its visitors [17]. The museum was not seen any more as a neutral institution but as a vital organism within the community that was located in socio-cultural, historical and political contexts. Museum professionals were concerned with the aesthetics of the museum space, the narratives and semiotics of displays. The museum's educational role was not merely to teach about the objects but to pose epistemological questions that generate a stimulating museum experience. As Hilde Hein states 'what is observed in the museum today is no longer unequivocally an object; objects have been reconstituted as sites or experience, and museums increasingly hold themselves accountable for delivering experiences' [18].

Socio-constructivist approaches also in the area of visitor studies research in museum studies changed the way the museum experience was conceptualised. Museums viewed the experience they deliver not as a set cultural product but as a process shaped through the interaction of the personal, social and physical contexts that are on interplay during the visit [19]. It is acknowledged that the visitors read the experience by drawing on their prior knowledge, preconceptions and experiences. These readings are also affected by the opportunities given for social interaction during and after the visit and the degree of comfort within the physical space of the museum. Within this interactive context that operates in the museum experience, learning is seen as informal and openended in its nature offering opportunities for intrinsic motivation and personalised engagement in opposition to formal curricula that have specific learning outcomes linked to standards and levels [20].

Hence a possible tension could be traced between the open ended nature of learning in museums and the learning in the ITT given that the second belongs to the realm of formal curricula. Within HE teaching, learning and assessment are interrelated in line with each programme's specifications. According to the Quality Assurance Agency Code of Practice, programmes of study are designed in line with the benchmark standards and have specific structures and requirements to enable each programme's outcomes to be achieved and demonstrated. As a result learners in $\mathrm{HE}$ are taught in timetabled sessions structured in a sequential manner to allow gradual engagement with certain concepts and achievement of specific learning outcomes. Yet, what seems to be a structured learning experience leaves space for self-directed study which however still succumbs to the needs of a structured assessment process. Perhaps, as highlighted by Boys (2010) there is a slipperiness of terminology when defining learning; the distinction between formal and informal learning in university study could be seen as artificial since 'we can learn informally through highly organised sequences of activities and undertake formal education through self-directed study' [21]. Undoubtedly there is an openness and variety in the learning approaches employed in University studies; however, one could not ignore the limitations that preset learning outcomes for assessment can place in the learning experiences offered to students and in particular to student teachers. ITT institutions, as also state-maintained schools, have to comply with the statutory requirements set by Ofsted, TDA and Dfes and follow reporting mechanisms that look for the impact that taught modules have on students' future practice in schools. Learning is orientated towards achievement/failure and the collection of relevant evidence.

The ITT agenda could have important implications for museum educators if museums are interested in offering educational services that respond to their audiences' needs. Student teachers are not merely an extension of other audiences from the educational sector but an audience with specific needs and interests. However, should and could museums rethink their offer to ITT and consider what counts as knowledge, as achievement and learning for students teachers marginalizing their role as places for inspirational learning and personalized engagement?

Perhaps to bridge perspectives both institutions should search for a dialogue beyond the institutional barriers in order to understand how they can work together extending each others' potential.

\section{The present study}

Within the rationale of embedding EOtC in student teachers' professional learning, a pilot research project took place in an ITT programme in a HE institution during the academic year 2009. The project funded by the MLA -South East aimed to offer the ITT the opportunity to discover more systematic ways of working with museums and archive venues. The collaboration with the local museums took place within the context of taught modules promoting specific links between the University's 'curriculum' and the museums' educational offer. It was expected that the students through their own enhanced learning experiences would value the power of learning in museums and promote it in their practice as professional teachers. Eighty nine students and seven tutors collaborated with six museums in the region.

The methodological framework was designed based on the principles of the appreciative inquiry. The institutions' own agenda was viewed as 'a mystery to be embraced' seeking to identify 
platforms for collaboration and 'transformational change' [22]. Research participants are encouraged to identify the positive, focus on what is possible and envision what might be in order to move toward this direction. They are encouraged to re-interpret their reality, become aware of what is already there with the view to make the necessary changes to move to what is dreamt of.

Students and tutors participated in qualitative semi-structured interviews to explore the nature of the museum learning experience, to discuss the potential of museums and archives to enrich the learning intentions in taught modules and by reflecting on past experiences and current partnerships to identify what constitutes 'good' practice in such collaborations. The students were also encouraged to reflect on the value of the experience for their own professional development as future teachers. The themes that emerged from such reflection opened the enquiry for interviews that were conducted with museum professionals to explore further the museum agenda on the notions of the educational offer and partnership.

\section{Findings and discussion}

The analysis of the interviews conducted with the museum professionals and the HE tutors who participated in the project revealed layers of collaboration amongst the institutions. Motivations for engaging in partnership varied both from the perspectives of the tutors and the museum professionals. The challenges to partnership were substantial but the benefits of collaboration also considerable. Three key themes emerged from the data analysis to point out the grounding that underpins such partnerships and to illustrate the value of the museum visiting experience for all stakeholders but in particularly for those immediate concerned: the student teachers.

\subsection{Shared understandings of pedagogy}

A mutual value on the interpretative processes behind the collections and a willingness to share expertise constitute the 'social glue' that held the organizations together to provide the basis for sustained partnerships.

When museums were willing to embark on a journey of open interpretive processes with their visitors they viewed partnership as a collaborative exploration both with the University tutors and students. Student teachers and tutors were seen as experts in the field of education who can offer 'fresh' perspectives in the interpretation of the collections. Museums viewed their own role and expertise as a mediatory bridge between the collections and the university's agenda and were interested in being engaged in collaborative activities building on the student teachers' prior knowledge and learning intentions. The museum professionals demonstrated real commitment in facilitating the students' systematic engagement with the search, research and interpretation of the collections. Their interest in searching for multiple narratives in the interpretation of the collections and commitment to collaboration with HE students allowed the students to conduct a series of visits within and beyond the scheduled by the University timetable. This type of collaboration needed to be equally supported by the University tutors who created the appropriate structure in the modules to encourage students to take responsibility for their own learning. The educational intentions were related to the nature of historical inquiry and the development of research skills while the students' independent work at the museums/archives was associated with a final assessed outcome that did not have the format of the traditional written assignment (e.g. an educational resource for children, a reflective portfolio documenting the thinking and learning processes).

The museum professionals commented that they learnt through and from their involvement in collaborative activities:

Museum Professional: .. it is like a breath of fresh air for us to work with prospective teachers. We gain insights into the interpretation of our collections from angles that have not previously considered. Through this project we realised that there is a clear link between our collections and the subject of citizenship [...] we intend to take this forward in the work we are doing with school groups to open the focus and the process of the inquiry [...]

However, only few museums have embraced their full educational potential [23]. It is not uncommon education to be seen as peripheral to the museum's purpose delivered as a product and not as an interpretative process that re-shapes the museum space. The privilege of curatorial knowledge over the polysemantic character of artefacts and the provision of multiple interpretative modes may be more manifested in museums where the division between educational and curatorial work is still pertinent to the museums' practice [24]. When in the context of this research, museum pedagogy was taking the form of a predetermined educational product that intended merely to 'educate' the visitors about its collections, the responsibility for a partnership seemed to lie on the side of the University tutors. The museum professionals considered that the tutors could either decide to follow the museum's educational programme for adults (when this existed) or since they are familiar with the needs of their students and their own curriculum University tutors could create 
from scratch their own museum visit. Where museum narratives are tightly focused on fixed meanings and educational objectives delivered in a didactic manner, visitors may feel uncomfortable or even excluded from the museum space unable to reach the high level of the presented scholarly knowledge. Some University tutors felt that they were lacking knowledge of how to work on their own with exhibits and collections and commented that the museum professionals were not in a position to view the partnership beyond the goals of their own institution and practices. Such approaches took the form of one off educational events, obviously posing difficulties for the formation of partnerships that create transformational changes in the involved institutions:

Tutor: I think what we were hoping for was a better understanding of the kinds of things, the possible opportunities, how they're linked to our curriculum or to the thematic strands we are exploring in our modules. [...] We don't have the familiarity of the exhibits, we don't have the time, if the truth be known we don't have the knowledge of the potential ... you do kind of rely on somebody at the museum to be the interface and I think that was lacking. I think the person who was there you know did his very best for us, don't get me wrong but I don't think that he was attuned to the requirements that were there. So it was a mixed outcome'.

One-off-visits were considered to be 'inspirational' only when the university tutors were seeking for a museum visit at the beginning or end of a module during which the museum experts would 'share their knowledge' with the students. Although, this type of events were designed entirely based on the museum's agenda, it was the style of the delivery, the emphasis on multiple narratives around the collections and the students' challenging engagement in debates and activities that made these programmes inspiring both for the tutors and students. However, these museum visits were not repeated the following academic year due to the temporary nature of the events; they relied on the museum's expertise and external funding to cover for the travel and the events' costs.

\subsection{Moving beyond pre-specified learning objectives}

The flexibility that usually underpins socioconstructivist ways of learning is a key element in reliving the tension that can be generated when both institutions have pre-specified educational objectives and outcomes. This element is important to be demonstrated not only by the museum professionals but also by the University tutors who are designing modules in line with the ITT programme's specifications. The set agenda on prescribed objectives and learning outcomes, especially when the museums intended to deliver their own cultural product, led to unfruitful collaborations. Only, when the tutors moved beyond the standards-driven culture that is still dominant in teachers' education today and viewed the educational practice in museums as 'an artful, emerging affair' they were in a position to create the open space required to integrate the museums' offer in the rationale of their modules and to promote self-directed study [25]. There was a shared belief amongst the University tutors who followed the open-ended approach that museum visits have an element of 'awe and wonder' that would be lost if the focus on set objectives and outcomes was predefined. It was expected that through the openness of the first hand experience and access to first hand resources the students could choose on what to focus on to make their own meaning:

Tutor: 'You're opening out the sort of potential for possibility. The idea that people are learning and taking from the experience, what they choose to take from the experience. For me that's the difference. [...] I have hopefully a fairly wide, broad aims [in the seminars] that you can then bring your own experience but there's something about being somewhere very different that means there's just potential for possibility. Who knows what might happen, what you might take from it'.

The students valued the openness in the enquiry since it allowed them to have autonomy in their learning journey. There is an understanding amongst the student teachers that museum projects might need a focus to work on, but it is the flexibility in the learning process that differentiates the learning experiences at museums from the learning experiences at the university:

ST1: And you directed what you wanted to do on it as well, nobody told you.

ST2: You kind of went wherever ...

ST1: Yes, what suited you to finding out.

ST2: It's like I started off on one place, and I kind of more ended up in another, but it doesn't matter because I can do it as a wide thing, or I can then say right we're narrowing down [...] rather than having to go a specific way the University would want me to go ... if you see what I mean.

ST1: It's autonomy then, that's what it is, it's the fact that we had autonomy to choose where we wanted to go and we had an idea that we were looking for primarily primary sources, so it was original pieces of material that we could 
use, but really it was up to us, and that was quite nice in a way.

\subsection{Shifting the dynamics of learning}

The learning space itself, being a museum or a seminar room, plays a dynamic role in the construction of social situations in it and impacts upon the process of education in it. One would expect, as stated by Montgomery (2008), that when higher education students become museum visitors as a group they may bring with them the socially constructed situation that exists in a seminar room; they still have a degree of obligation to their peers, to the tutor and to the learning process. However the actual physical space has an effect on the pedagogy followed and makes explicit issues of power [26]. Indeed, both the tutors and students' reflections on the visits suggest that there was a shift in the dynamics of learning during the visit. The tutors commented that during the students' self-directed study in the museum space or participation in activities led by the museum professionals they 'were learners alongside the students'. As the following extract illustrates they felt that they repositioned their tutor identities in the group and also saw the students' potential via a different perspective:

Tutor: 'I wasn't there in the role of tutor imparting knowledge as they might typically see you [...] I was just as in awe of the text that they were looking at and then, I, I mean I was amazed, I was blown away by some of the students knowledge of text and books and their passions for reading [...] and I was having a go as much as the students were and I was getting wrong as much as the students were (laugh)'

The student teachers also viewed their learner identities via a 'different' gaze and valued the learning experience at the museum for: a) its 'autonomy', b) its multidimensional nature, c) its opportunity to 'connect' with the real object. The engagement in discussion and debates with experts enabled them to use terminology and share knowledge in the field they specialize. This interaction with experts allowed them to feel valued as experts themselves. The student teachers' professional identity was strengthened and they felt that the learning experiences had the potential to be deeper than the learning experiences at seminar rooms:

ST: 'But also you felt artier, that you were more of an artist for being in a gallery than being in a seminar room on University campus' [...] because of her knowledge of the painting she was able to allow us to have greater discussion about them, and from that we felt more like we were operating as artists .... So when it came to doing practical work you felt like more of an artist'.

ST: 'I would say from having, from going to the library and learning about literature, how important it is like to write in the books and like the language, I learnt a lot more in that one day than I did last year in semester learning about language origins'.

\section{Conclusion}

Museums and ITT institutions are being challenged to form sustainable partnerships. Existing discourses in museums about its purpose and communication as an institution are likely to create the conceptual space and the infrastructure for provision for HE students. However, this is not a panacea for all museums and collaborations with HE. Shared values and philosophies around learning need to underpin the grounding of partnership. ITT institutions are a distinct audience in the sense that it has its own particularities, needs and purposes. There are institutional barriers that University tutors and students have to face including the set timetables, the reduction of funding for activities 'outside the classroom' and the tight link amongst teaching, learning objectives and assessed outcomes.

As suggested in this research, it is the openness of the experience in a 'different' learning environment that tutors valued than the adherence to preset learning objectives and outcomes. The student teachers valued the opportunities given for independent study during which university tutors and museum professionals were facilitators. The sharing of expertise and knowledge amongst all parties involved in the partnership shifted the dynamics of learning that usually occurs in seminar rooms. It offered opportunities for autonomy in the learning process and engagement with real objects and stories that are not easily available within the University space. The student teachers not only valued the experience of learning in the museum as learners, prospective teachers bur also as professionals who specialize in their chosen area of subject knowledge.

Perhaps before searching for models for collaboration on a managerial level that will perpetuate the current prescribed ITT agenda in a different setting, we need to unpack the complexity of the collaborative learning experience that both sectors are called to form. The mapping of the activities directly to sector standards (as suggested in the current TOtC guidance) might allow the students to add 'evidence' in their portfolios to claim the QTS status. The 'planning for longitudinal evaluation of the impact on trainees' might provide a perspective into the power of museum learning [15]. However, we should not override the possibility that such 
approaches could limit the flexibility and the space required to explore the potential for collaborative learning that broadens the horizons of the institutions. A dynamic dialogic space in which museums and ITT have a common vision in terms of the students' participation, view their own role as a facilitatory one, and are interested in deepening the praxis of the individual student teacher in the museum learning experience, might be a priority for the forming of meaningful partnerships especially within a period of financial hardship both for the educational and cultural sector.

\section{References}

[1] DCMS, Centres for Social Change: Museums, Galleries and Archives for All. DCMS Publications, London, 2000

[2] DCMS, Understanding the Future: Priorities for England's Museums. DCMS Publications, London, 2005

[3] National Council on Archives, NCA's response to the DCMS' second consultation on "Understanding the Future: Priorities for England's Museums" http://www.nca.org.uk/advocacy/consultations/, last accessed on $06 / 06 / 10$

[4] Speight C., Museums and Higher Education: A New Specialist Service? In Cook B., Reynolds R., and Speight C. (eds) Museums and Design Education. Looking to Learn, Learning to See. Ashgate, Farnham, 2010

[5] Anderson D., A Common Wealth: Museums and Learning in the United Kingdom. Department of National Heritage, London, 1997

[6] Larson F, Petch A., and Zeitlyn D., 'Social Networks and the creation of the Pitt Rivers Museum'. Journal of Material Culture, 12 (3), 2007, p.p.211-239

[7] Cook B., Reynolds R., and Speight C. (eds) Museums and Design Education. Looking to Learn, Learning to See. Ashgate, Farnham, 2010

[8] Jacobs C., 'Beyond the filed trip: museum literacy and higher education'. Museum Management and Curatorship, 24 (1), 2009, p.p.5-27

[9] Smith L. and Walker K., 'Going Dutch: the development of collaborative practices between higher education and museum and galleries', JADE 22(1), 2003, p.p.36-46

[10] Boys J., Creative differences: Deconstructing the Conceptual Learning Spaces of Higher Education and Museums, in Cook B., Reynolds R., and Speight C. (eds) Museums and Design Education. Looking to Learn, Learning to See. Ashgate, Farnham, 2010

[11] Cook R.. and Speight C. Bridging Perspectives Approaches to Learning in Museums and Universities, in Cook B., Reynolds R., and Speight C. (eds) Museums and
Design Education. Looking to Learn, Learning to See. Ashgate, Farnham, 2010

[12] DCMS, Understanding the Future: Priorities for England's Museums. DCMS Publications, London, 2005, p.20

[13] Museums, Libraries and Archives (MLA) http://www.mla.gov.uk/what/programmes/commissio ning/Initial_Teacher_Training, last accessed on $28 / 03 / 11$

[14] Kendall S., Murfield J., Dillon J., Wilkin A. Education Outside the Classroom: Research to identify what training is offered by initial teacher training institutions, DfES, London, 2006

[15]Teaching Outside the Classroom (TOtC), http://www.teachingoutsidetheclassroom.com/, last accessed on $28 / 03 / 11$

[16] Eisner W.E., Reimagining Schools. Routledge, London \& New York, 2005, p.25-p.26

[17] Hooper-Greenhill E., Museums and Education, Routledge, London \& New York, 2007, p.1

[18] Hein H., The Museum in Transition, Smithsonian Books, Washington, 2005, p.5

[19] Falk H.J., and Dierking D. L. , Learning from Museums, AltaMira Press, Oxford, 2000

[20] Hooper-Greenhill E., Museums and Education, Routledge, London \& New York, 2007

[21] Boys J., Creative differences: Deconstructing the Conceptual Learning Spaces of Higher Education and Museums, in Cook B., Reynolds R., and Speight C. (eds) Museums and Design Education. Looking to Learn, Learning to See. Ashgate, Farnham, 2010, p.54

[22] Grant S. and Humphries M. Critical Evaluation of Appreciative inquiry: bridging an apparent paradox, Action Research 4 (4), 2006, p.403-p.404

[23] Hooper-Greenhill E. The Power of Museum Pedagogy, in Genoways H.H., (ed.) Museum Philosophy for the Twenty-first Century, Oxford, AltaMira, 2006

[24] Witcomb A., Re-imagining the Museum - beyond the Mausoleum. Routledge, London, 2002

[25] Eisner W.E., Reimagining Schools. Routledge, London \& New York, 2005, p.28

[26] Montgomery T. 'Space Matters: Experiences of managing static formal learning spaces'. Active Learning in Higher Education 9 (2), 2008, p.p. 122-138 